\title{
Clinicopathological Evaluation of 50 Cases of Unicystic Ameloblastoma in Indian Population
}

\author{
Dr. Suvarna Manthapuri ${ }^{1 *}$, Dr. Shylaja Sanjeevareddygari MDS $^{2}$, Dr. Harshini Mantha, BDS ${ }^{3}$ \\ ${ }^{1}$ Associate Professor, Department of Oral Pathology and Microbiology, SVS Institute of Dental Sciences, Mahabubnagar - Jadcherla Rd, Housing \\ Board Colony, Yenugonda, Mahbubnagar, Telangana 509001, India \\ ${ }^{2}$ Professor and Head, Department of Oral Pathology and Microbiology, SVS Institute of Dental Sciences, Mahabubnagar - Jadcherla Rd, Housing \\ Board Colony, Yenugonda, Mahbubnagar, Telangana 509001, India \\ ${ }^{3}$ Post Graduate Trainee, Department of Oral Pathology and Microbiology, SVS Institute of Dental Sciences, Mahabubnagar - Jadcherla Rd, Housing \\ Board Colony, Yenugonda, Mahbubnagar, Telangana 509001, India
}

\begin{tabular}{ll}
\hline DOI: $10.36348 /$ SJODR.2019.v04i09.010 & | Received: 08.09.2019| Accepted: 14.09.2019| Published: 30.09 .2019
\end{tabular}

*Corresponding author: Dr. Suvarna Manthapuri

\section{Abstract}

Background: Unicystic ameloblastoma is one of the different clinical variants of ameloblastoma which is less aggressive in its biological behavior. Aim: The present study was undertaken to retrospectively compare the clinical, radiologic, and histopathologic features of 50 cases of unicystic ameloblastoma in Indians. Methods: Biopsy records of 50 histologically diagnosed cases of unicystic ameloblastoma over 9-year (2010-2019) period were retrieved and analyzed for age, sex, site distribution, clinical presentation, radiologic features, and histopathology. Results: It was revealed that out of 50 cases, a male preponderance was seen. Age predisposition was seen to favor the $2^{\text {nd }}$ to 3 rd decade, the most common site was the posterior aspect of lower jaw. Common histological type noted was luminal and intramural type (1.3). Conclusion: The study provides baseline data regarding the viable record for the distribution of odontogenic lesions in the sample population.

Keywords: Unicystic Ameloblastoma, Odontogenic tumor, Biological behavior.

Copyright @ 2019: This is an open-access article distributed under the terms of the Creative Commons Attribution license which permits unrestricted use, distribution, and reproduction in any medium for non-commercial use (NonCommercial, or CC-BY-NC) provided the original author and source are credited.

\section{INTRODUCTION}

Unicystic ameloblastoma, shows slow growth and is relatively locally less aggressive [1]. As it macroscopically appears well defined and microscopically shows luminal or focal presence of ameloblastomatous epithelium it was named as unicystic ameloblastoma. It also often shows presence of epithelium of varying histologic appearance mimicking the lining of a dentigerous or radicular cyst [2].

It shows three histological subtypes luminal, intraluminal, and mural types according to the degree of ameloblastomatous epithelial extension with variation in their biological behavior [3]. Later this histological classification of unicystic ameloblastomas is modified as sub group 1-luminal, sub group 1.2- luminal and intraluminal, sub group-1.2.3-as luminal, intraluminal and intramural and sub group 1.3- luminal and intramural types [4]. Unicystic ameloblastomas in Indians have been less studied. So the present study was undertaken to ascertain the clinicomorphologic spectrum of this tumor group.

\section{MATERIALS AND METHODS}

For the analysis of clinical data, biopsy records of 50 histologically diagnosed cases of unicystic ameloblastoma over a 9year period were retrieved from the archives of the Department of Oral and Maxillofacial Pathology, SVS institute of Dental Sciences, Mahabubnagar, Telangana. Data with respect to the patients' age, sex, site distribution, clinical presentation, association with impacted tooth, radiologic features, and histopathology were analyzed.

\section{RESULTS}

Of total 86 cases of ameloblastomas reported within the period 2010 to $2019,50(58.13 \%)$ cases were diagnosed as unicystic ameloblastomas. The clinical, radiological and histological features of these 50 cases were reviewed. The most common affected age group was 11-20 years (32.6\%) followed by $21-30$ years $(26 \%)$ as shown in graph-1. 


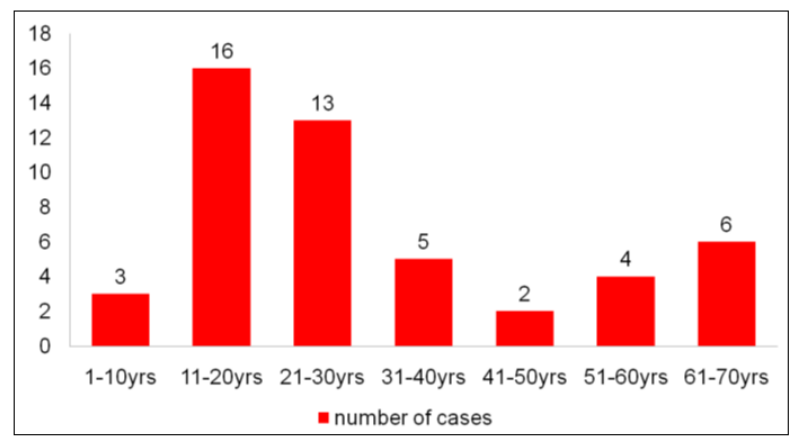

Graph-1: Age distribution of all the cases

Males (64\%) were most commonly affected compared to females (36\%) as depicted in Graph-2.

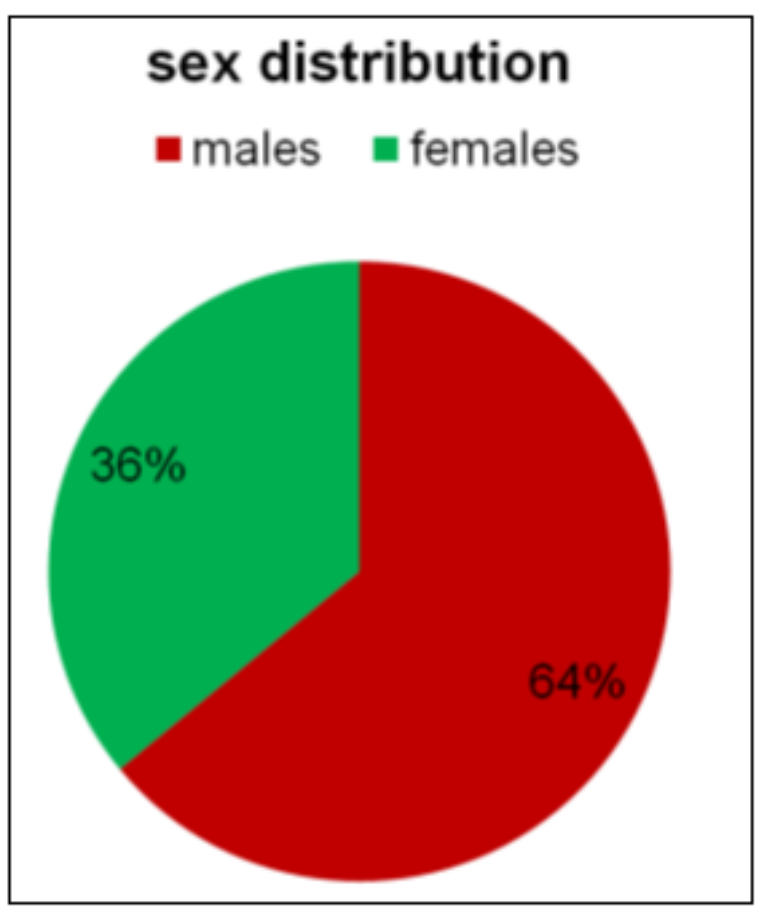

Graph-2: Sex distribution of all cases

Most of the cases were involving mandible $(80 \%)$ with posterior mandible (64\%) being the most common site. All cases were presented as swellings with few associated with pain. Out of 50 cases $7(14 \%)$ cases showed association with impacted tooth and $1(2 \%)$ case showed presence of supernumerary tooth. On radiographic examination $23(46 \%)$ cases presented as unilocular radiolucencies where as 8 cases $(16 \%)$ showed multilocular radiolucency.

On histological evaluation of the cases, most common histological type noted was luminal and intramural type (1.3). This type of proliferation is shown by 19 (38\%) cases followed by luminal, intraluminal and mural proliferation (1.2.3) (Figure-1) consisting of 14 cases (28\%). Least common histological type seen was luminal and intraluminal type (1.2). Only 7(14\%) cases out of 50 showed this type of proliferation.

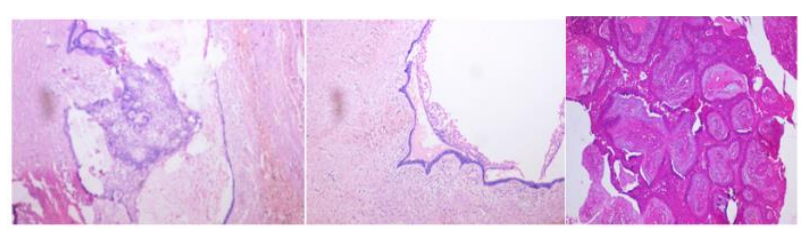

Fig-1: Histopathology showing intraluminal, luminal and mural proliferation of ameloblastomatous epithelium

\section{DISCUSSION}

Unicystic ameloblastoma was first described by Robinson and Martinez in $1977^{2}$. Evolution of Unicystic Ameloblastomas can be explained by the following three pathologic mechanisms ${ }^{2}$.

- The reduced enamel epithelium associated with the developing tooth undergoes ameloblastic change with subsequent cystic transformation.

- Ameloblastomas arise in dentigerous or other types of odontogenic cysts in which the neoplastic ameloblastic epithelium is preceded temporarily by a non-neoplastic stratified squamous lining.

- Solid ameloblastoma undergoing cystic degeneration of ameloblastic islands with subsequent fusion of multiple microcysts and then into a unicystic lesion.

It accounts for $10-15 \%$ of all intraosseous ameloblastomas3. But we reported a higher incidence, almost half $(58 \%)$ cases were reported as unicystic out of 86 cases of intraosseous ameloblastomas. The clinical features obtained in our study were coinciding with most of the studies. In this study the most common age group affected is 11 to $30 \mathrm{yrs}$, with a mean age of 34 yrs. We noted a slight male predilection and the most common site involved is posterior mandible. Radiographically majority of the cases presented as unilocular radiolucencies.

These results are coinciding with the studies carried out by Ackerman GL et al., [3], LI TJ et al., [5], Bogahawatte Samarakoon Mudiyanselage Samadarani Siriwardena et al., [6] and Philipsen HP et al., [2], Ogunsalu C [7] and Alan S. Leider [8].

The association with impacted tooth is found to be $14 \%$ in the present study whereas Philipsen HP $e t$ al., [2] noted an association with impacted tooth as between 50 to $80 \%$. This indicates a geographical variation in different sample populations and discrepancies in size of the sample.

Most common histological type seen in the present study was type 1.3 (luminal and intra mural) according to philipsen [4] classification. Bogahawatte Samarakoon Mudiyanselage Samadarani Siriwardena et al., [6] noted majority cases as luminal type followed by mural proliferations and Ackerman GL et al., [3] 
noted slightly higher number of mural type of proliferations followed by luminal type.

It has been widely stated that these lesions are less aggressive than their solid or multicystic counterparts and should be treated by enucleation or curettage. However, Gardner in 1984 has pointed out difference in biological behavior between different histological variants. According to him lesions showing mural proliferations should be treated more aggressively than simple cystic type as they have capacity to invade the underlying cancellous bone [9].

\section{CONCLUSION}

The study results analyzing the clinicopathological parameters of unicystic ameloblastoma could act as a viable record for the distribution of these odontogenic lesions in the sample population. The clinical epidemiologic profile of patients from the present study is very similar to other populations with regard to gender, age, and tumor location, with some differences, in histological subtypes. Our study also highlights the increasing incidence of unicystic ameloblastomas among solid ameloblastomas.

\section{REFERENCES}

1. Hsu, M. H., Chiang, M. L., \& Chen, J. K. (2014). Unicystic ameloblastoma. Journal of Dental Sciences, 9(4), 407-411.

2. Reichart, P. A., Philipsen, H. P., \& Sonner, S. (1995). Ameloblastoma: biological profile of 3677 cases. European Journal of Cancer Part B: Oral Oncology, 31(2), 86-99.

3. Ackermann, G. L., Altini, M., \& Shear, M. (1988). The unicystic ameloblastoma: a clinicopathological study of 57 cases. Journal of Oral Pathology \& Medicine, 17(9-10), 541-546.

4. Philipsen, H. P., \& Reichart, P. A. (2004). Unicystic ameloblastoma. In: Odontogenic tumors and allied lesions. London: Quintessence Pub. Co. Ltd; 77-86.

5. Li, T. J., Wu, Y. T., Yu, S. F., \& Yu, G. Y. (2000). Unicystic ameloblastoma: a clinicopathologic study of 33 Chinese patients. The American journal of surgical pathology, 24(10), 1385-1392.

6. Siriwardena, B. S. M. S., Tennakoon, T. M. P. B., Hunter, K. D., \& Tilakaratne, W. M. (2018). Unicystic ameloblastoma: Analysis of 370 cases in a single center in Sri Lanka. Journal of Oral Pathology \& Medicine, 47(7), 706-709.

7. Ogunsalu, C., West, W., Lewis, A., \& Williams, N. (2011). Ameloblastoma in Jamaicapredominantly unicystic: analysis of 47 patients over a 16-year period and a case report on re-entry cryosurgery as a new modality of treatment for the prevention of recurrence. West Indian Medical Journal, 60(2), 240-246.

8. Leider, A. S., Eversole, L. R., \& Barkin, M. E. (1985). Cystic ameloblastoma: a clinicopathologic analysis. Oral surgery, oral medicine, oral pathology, 60(6), 624-630.

9. Gardner, D. G. (1984). A pathologist's approach to the treatment of ameloblastoma. Journal of oral and maxillofacial surgery, 42(3), 161-166. 